Marine Geodesy

September 2015, Volume 38 Issue Suppl.1 Pages 449-465

http://dx.doi.org/10.1080/01490419.2014.1000470

http://archimer.ifremer.fr/doc/00286/39675/

(C) Taylor \& Francis Group, LLC

\title{
Assessment of SARAL/AltiKa Wave Height Measurements Relative to Buoy, Jason-2, and Cryosat-2 Data
}

\author{
Hito Sepulveda Hector ${ }^{1}$, Queffeulou Pierre ${ }^{2,{ }^{*}}$, Ardhuin Fabrice ${ }^{2,3}$ \\ ${ }^{1}$ Univ Concepcion, Dept Geophys, Concepcion, Chile. \\ 2 IFREMER, Lab Oceanog Spatiale, F-29280 Plouzane, France. \\ ${ }^{3}$ CNRS Ifremer UBO IRD, UMR 6523, Lab Phys Oceans, Brest, France. \\ *Corresponding author : Pierre Queffeulou, email address : pierre.queffeulou@ifremer.fr
}

\begin{abstract}
:
SARAL/AltiKa GDR-T are analyzed to assess the quality of the significant wave height (SWH) measurements. SARAL along-track SWH plots reveal cases of erroneous data, more or less isolated, not detected by the quality flags. The anomalies are often correlated with strong attenuation of the Kaband backscatter coefficient, sensitive to clouds and rain. A quality test based on the $1 \mathrm{~Hz}$ standard deviation is proposed to detect such anomalies. From buoy comparison, it is shown that SARAL SWH is more accurate than Jason-2, particularly at low SWH, and globally does not require any correction. Results are better with open ocean than with coastal buoys. The scatter and the number of outliers are much larger for coastal buoys. SARAL is then compared with Jason-2 and Cryosat-2. The altimeter data are extracted from the global altimeter SWH Ifremer data base, including specific corrections to calibrate the various altimeters. The comparison confirms the high quality of SARAL SWH. The $1 \mathrm{~Hz}$ standard deviation is much less than for Jason-2 and Cryosat-2, particularly at low SWH. Furthermore, results show that the corrections applied to Jason-2 and to Cryosat-2, in the data base, are efficient, improving the global agreement between the three altimeters.
\end{abstract}

Keywords : Radar altimeter, significant wave height, satellite, SARAL, AltiKa, validation 


\section{1- Introduction}

The AltiKa radar altimeter was launched on February 25th, 2013, on the SARAL mission, a cooperative project between the Indian Space Research Organization (ISRO) and the French space agency Centre National d'Etudes Spatiale (CNES). Technical description of the altimeter and of the mission can be found in Verron et al. (this issue). AltiKa is operated at Ka-band (35 $\mathrm{GHz}, 0.8 \mathrm{~cm}$ wavelength) a higher frequency than all previous satellite altimeters, operating at $\mathrm{Ku}$-band (13,6 GHZ, $2.2 \mathrm{~cm})$ and using secondary frequency at C-band or S-band to correct for ionospheric attenuation. Using $\mathrm{Ka}$-band frequency enables a low ionospheric attenuation and better altitude and along-track spatial resolutions than at $\mathrm{Ku}$-band (Vincent et al. 2006). Using a higher frequency, jointly with technological innovations, lead to several improvements of Altika performances, relative to conventional Ku-band altimeter, for both sea level and significant wave height (SWH) measurements (Vincent at al. 2006, Raney and Phalippou 2011 ). First, increasing the frequency bandwidth results in a better height resolution $(31 \mathrm{~cm}$ instead of $45 \mathrm{~cm}$ at Ku-band) and a smaller pulse limited footprint. Second, a smaller antenna beam-width reduces the measurement footprint to $8 \mathrm{~km}$ in diameter, instead of $21 \mathrm{~km}$. Third, a higher pulse repetition frequency $(4 \mathrm{kHz})$ increases the number of individual waveforms for averaging, with improvement of SWH estimate accuracy. Fourth, the tracking performances are improved, with a resulting better monitoring of changing surface elevations, in particular at coastal transitions. Past altimeter missions have largely demonstrated the accuracy (Queffeulou 2004, Zieger et al. 2009, Durant et al. 2009, Ray and Beckley 2012) and the usefulness of satellite altimeter wave height measurements in various research areas like wave observation and climate (Cooper and Forristall 1997, Young et al. 2011), and numerical wave modelling (Rascle and Ardhuin 2013et al. 2008 , Skandrani et al. 2009, Abdalla et al. 2010, Ardhuin et al. 2011). Up to now, coastal altimeter SWH measurements were not considered because of land eontamination of the altimeter signal. Up to now, very coastal altimeter SWH measurements were not considered. In coastal waters the altimeter signal is contaminated by land because of the large antenna footprint and sidelobes. Coastal measurement performance depends also on the agility of the tracker to recover the signal, at the transition from the land to the sea. The height scale of the coastal topography has a significant impact on the coastal measurement perturbation. Indeed, cE Comparisons with coastal buoy measurements indicate dramatic biases and errors in the altimeter measurements, relative to the coastal ones (Shanas et al. 2014), and this is mainly 
because in such comparisons, in order to be free from land contamination, altimeter data are necessarily limited to offshore areas (at least $50 \mathrm{~km}$ ), where sea state conditions can be very different from the coastal ones. With SARAL one can expect improvements in wave height measurement at low sea state because of better height resolution, and in coastal areas because $\underline{\text { smaller footprint and better tracking. }}$

Nevertheless the main and serious drawback of Ka-band is a larger signal attenuation by the atmospheric vapour and liquid water content (clouds and rain). In strong rain events, the signal attenuation results in distortion of the return waveform (Tournadre et al. 2009), inducing erroneous wave height estimates.

First SARAL Intermediate Geophysical Data Records (IGDR) were made available rapidly after launch, and preliminary wave height validation studies have shown the global good accuracy of SARAL significant wave height (SWH) measurements, but have also revealed the effects of rain attenuation on SWH measurement quality (Queffeulou 2013-a). After the commissioning phase a new reprocessed data set, Geophysical Data Records in version "T" (GDR-T), was made available $(G D R-T)$ from the beginning of the mission.

The aim of the present paper is to validate the SARAL GDR-T SWH data, firstly to assess the quality and particularities of the SARAL AltiKa measurements, and, secondly, with the goal of implementing the SARAL wave height measurements in the global merged altimeter wave height data set, developed at Ifremer. For this purpose, SARAL SWH measurements are compared with buoy data, and with altimeter measurements from Jason-2 and Cryosat-2. Section 2 describes the various data set used in the study, and the quality test processing, when needed. Section 3 shows the data screening and quality tests performed over SARAL SWH data before comparison with other sources. Results of comparisons are shown and discussed in section 4, for buoy data, and in section 5 for Jason-2 and Cryosat-2-comparisons.

\section{2- Data and processing}

\section{Altimeters}

SARAL data are the GDR in version T (SARAL/AltiKa Products Handbook 2013), collected on the AVISO ftp, for cycle number 1 to 12 , covering the 14 month time period from March 14th, 
2013 to May 8th, 2014.

Jason-2 and Cryosat-2 data are from the merged SWH altimeter data base developed at Ifremer (Queffeulou and Croizé-Fillon, 2013) - described here under, and also distributed within the Globwave project (www.globwave.org). In the data base, Jason-2 data are the GDR-D provided by AVISO (Picot et al. 2003), and Cryosat-2 data (Francis et al. 2007) are the IGDR processed and provided by the NOAA Laboratory for Satellite Altimetry

(ftp://ftp.star.nesdis.noaa.gov/pub/sod/lsa/cs2igdr/).

Because altimeter SWH data are issued from various altimeters (more than 10 altimeter missions were operated since 1991), in various formats, and with various quality flags, it was suitable to develop a merged, calibrated and homogeneous SWH data base, easily accessible by potential users. Over the whole altimeter missions, using dedicated quality flags does not always suppress erroneous SWH data and some time does suppress valid SWH data. Editing criteria found in user's manuals, as for instance considering only data with SWH less than $11 \mathrm{~m}$, are valid for mesoscale sea level studies but not for SWH activity. Indeed, SWH values up to $20 \mathrm{~m}$ have been shown to be of good quality and consistent with other observations (Hanafin et al. 2012).

To set up the merged data base, basic quality flags are tested (land, ice), and specific flags are also considered for some altimeters. After this step, many erroneous data still remain, due to land contamination, strong rain attenuation, and sigma0 blooms, for example-...

Analysis of the data reveals that the standard deviation of SWH values over $1 \mathrm{~s}$ is the most relevant parameter to detect erroneous values of SWH. For most altimeters the most widely used SWH data is estimated over $1 \mathrm{~s}$ along-track measurements (called $1 \mathrm{~Hz}$ data) as the mean value of a number of individual SWH estimated from the analysis of the return waveform. The number of individual measurements over $1 \mathrm{~s}$ depends on the altimeter technology and processing: 20 for Jason-1\&2 and 40 for SARAL. Together with the mean value, the $1 \mathrm{~Hz}$ standard deviation (hereinafter called the rms) is available, and is a good indicator of the SWH measurement quality. The rms level depends also on SWH, due to both instrument and geophysical sea surface height variability (at the wave height scale). For a given narrow SWH bin range the distribution of the rms is not Gaussian, but the distribution of the logarithm is generally more Gaussian. This 
ebservation property can be used to estimate a maximum threshold value for the logarithm of SWH rms as the sum of the mean value and twice or 3 timesthrice the standard deviationthis factor is adjusted empirically for each altimeter - the standard deviation. From that, a maximum threshold is then estimated for the SWH rms itself. This technique was applied for the data base, producing a specific SWH rms threshold for each altimeter.

Applying this threshold, very few isolated spurious data still remain and are eliminated using the following specific filter. For each altimeter measurement, a neighbouring data set is constructed in selecting all the along-track data over $100 \mathrm{~km}, 50 \mathrm{~km}$ each side of the considered point, resulting in a 14 to 17 measurement data set, depending on the satellite. Then the two extreme values of this data set are discarded for computing mean value and standard deviation. Lastly the considered measurement is tested relatively to the range defined by the mean value plus or minus four times (can be adjusted empirically, depending on altimeter) the standard deviation. The measurement is discarded if outside this range.

After this cleaning procedure, biases and trends are analysed for the various satellites. To calibrate the data, buoy comparisons, and cross-altimeter comparisons are generally performed. Numerical wave models are also used for quality assessment (Abdalla et al. 2010). Dedicated studies proposed various altimeter SWH corrections (Zieger et al. 2009, Durant et al. 2009). In the data base, specific SWH corrections (Queffeulou and Croizé-Fillon 2013) are applied, and updated on a regular basis.

For Jason-2 (GDR-D), the correction is linear, and rather small (a few $\mathrm{cm}$ to $20 \mathrm{~cm}$ ): swh_cor $=1.0149 \times \mathrm{xwh}+0.0277$ Cryosat -2 exhibits a non linear bias at low SWH (+10 to $-30 \mathrm{~cm}$ for SWH less than $2 \mathrm{~m})$, and a new correction was proposed for this (Queffeulou 2013-b) :$\underline{\text { swh cor }=0.4889+0.4712 \times \mathrm{swh}+0.1546 \mathrm{x} \mathrm{swh}^{2}-0.0145 \mathrm{x} \mathrm{swh}^{3} ; \text { for } \mathrm{swh} \leq 2.45 \mathrm{~m}}$ $\underline{\text { swh }}$ cor $=-0.1057+1.0058 \times$ swh; for $\operatorname{swh}>2.45$

\section{Buoys}

The buoy data set consists in the raw observations collected by ECMWF between March and December 2013, as part of their ocean wave forecast inter-comparison project (Bidlot et al. 
2002, J. Bidlot, personal communication 2013). It includes a combination of buoy records, platform observations, and ship reports from several countries, thus the total number of buoys changes every month.

\section{Of 559 buoys, 137 reported SWH data. Of those, 22 were considered as potential moving platforms/ships/buoys due to the large change in their reported positions and were discarded- after visual inspection of the reported latitude and longitude. For 10 buoys no collocation with SARAL satellite data was obtained and they were also discarded. For the remaining buoys, those reporting slight changing positions, the average position was considered for collocation- purposes. The resulting data set for collocation consists in a maximum of 375 buoys. For the buoy per buoy analysis, buoys with less than 6 collocations pairs were not considered. Out of 559 buoys 375 are used for preparing collocation data sets. Rest of the buoys either has} large drifts or does not collocate with SARAL.

It was not possible to control the quality of each buoy record as the provided data were in raw format. Buoy satellite collocated pairs whose difference was outside the range defined by the mean value plus or minus twice standard deviation, were identified as possible outliers. These outliers represent about $4 \%$ of the total for both SARAL and Jason-2. This approach is helpful to discard not only data from buoys with possible instrumental errors but also data from buoys whose measurements are not representative of local surrounding wave environment, such as buoys in protected areas of a harbour. In order to understand the impact of this quality control step, the statistical parameters were calculated with and without the excluded data pairs (Table 1). A more refined approach would require to inspect the data set and to select the buoys to be excluded individually.

To check SARAL's measurement quality in coastal waters, the location of each buoy was visually inspected and then buoys were separated into coastal, those within less than $50 \mathrm{~km}$ from the coast, and oceanic buoys.

\section{3- SARAL SWH data screening and quality control}


SARAL SWH data were analysed, in some empirical sense, to eliminate the erroneous data which are not detected by the quality flags given in the product. An example of SWH anomalies, not detected by quality flags, is given in Figure 1, for SARAL pass number 954, cycle number 2. This particular pass was selected for illustration (many other cases are available) because Jason2 measurements (pass 244, cycle 179) are available at the same time, close to the observed anomalies. The two altimeter tracks cross in open ocean, near $0.9^{\circ} \mathrm{S} 77^{\circ} \mathrm{E}$, on May 21st, 2013, at 12:59:32 for SARAL, and 7 minutes later for Jason-2. Along-track measurements between $2^{\circ} \mathrm{S}$ and $4^{\circ} \mathrm{N}$, covering about $700 \mathrm{~km}$, are shown in Figure 1.

SARAL SWH (black dot) exhibits three large spikes, in a global almost constant SWH background about $2 \mathrm{~m}$. A first spikeøne occurs over several consecutive $1 \mathrm{~Hz}$ measurements, with a maximum value of $7 \mathrm{~m}$ atby $0.7^{\circ} \mathrm{S}$ latitude. Two other spikes, more narrow, with maximum value between $8 \mathrm{~m}$ and $9 \mathrm{~m}$, are observed by $2.6^{\circ} \mathrm{N}$ and $3.4^{\circ} \mathrm{N}$. The Jason-2 collocated SWH measurements (grey dot) does not show such anomalies, though some larger scatter is present in the first anomaly area. These SWH spikes are strongly correlated with the atmospheric liquid water content (rain and clouds), as shown by the atmospheric attenuation correction applied to the SARAL backscatter coefficient (grey plus symbol). This correction, available in the SARAL data product, is estimated from the liquid water content provided by the radiometer measurements. The anomalies correspond to attenuation correction about $12 \mathrm{~dB}$, which is very large comparing to a background about $11 \mathrm{~dB}$ for the Ka backscatter coefficient. Such attenuation modifies the shape of the altimeter return waveform, inducing erroneous SWH estimates. Among the parameters that could be used to detect effectively such anomalies and to suppress erroneous data (number of valid data used to estimate the $1 \mathrm{~Hz}$ mean SWH, attitude angle, liquid water content, SWH quality flag_etc...) the standard deviation of SWH (hereinafter SWH rms) appears to be the more relevant variable. The SARAL SWH rms (black circle in Figure 1) is very sensitive to the anomalies, while the Jason-2 SWH rms (grey circle), at $\mathrm{Ku}^{-}$ band, is less perturbed thant at Ka-band.

A global analysis of the $1 \mathrm{~Hz}$ (SWH, rms) pairs was performed over 5 months (cycle number 4 to 8), representing 4.5 million of $1 \mathrm{~Hz}$ ocean data. The following flags and conditions were tested to select the data: open ocean or semi enclosed sea, number of individual values for $1 \mathrm{~Hz} \mathrm{SWH}$ 
estimates equal to 40, SWH rms non equal to zero, and absolute value of the attitude angle waveform less than or equal to 0.01 degree square. The attitude angle waveform is the angle of the antenna pointing, relative to the vertical, estimated from the analysis of the altimeter return waveform. In practice, the square of this quantity is estimated, and considered.

The (SWH,rms) distribution is shown in Figure 2 for $0.01 \mathrm{~m} \mathrm{x} 0.01 \mathrm{~m}$ bins. For convenience the figure has been zoomed, but numerous isolated data points exist up to $9 \mathrm{~m}$ in rms. Three patterns can be distinguished. The main one in the global axis of the distribution, indicates that the rms increases with SWH. A secondary pattern consists in large, scattered, rms values, above the red curve, for SWH range about 1-9 m, extending up to $9 \mathrm{~m}$ rms well beyond the upper limit of the figure. Most data of this second pattern correspond to along-track, almost isolated, erroneous spikes. A third pattern in the bottom left side of the figure, shows a specific non-linear behaviour of the rms at very low sea state, in the first $1.5 \mathrm{~m} \mathrm{SWH}$ range. This feature is also observed in other altimeters (Queffeulou 2013-a) at different low SWH ranges, and may be due to the waveform processing.

The red curve in Figure 2 corresponds to the rms threshold value estimated from the distribution of the logarithm of the rms, for each $0.1 \mathrm{~m} \mathrm{SWH}$ bin. Data above the red curve are considered erroneous. At high SWH the red curve becomes very noisy, mainly because of a relatively low number of data. In practice, the rms threshold is estimated by the real values given by the red curve for SWH less than or equal to $2.5 \mathrm{~m}$. Between $2.5 \mathrm{~m}$ and $12 \mathrm{~m}$, the red limit is approximated by a third order polynomial fit. Then the threshold is set to a constant value (1.85 m) for SWH larger than $12 \mathrm{~m}$.

This threshold filter is applied to the SARAL GDR-T before comparisons with buoy data, in section 4, and with Jason-2 and Cryosat-2 altimeter data in section 5.

\section{4- Buoy comparison}

SARAL and Jason-2 measurements were collocated with the selected buoys data. For each buoy observation, altimeter measurements within a 30 minute time window from the buoy measurement, and $50 \mathrm{~km}$ from the buoy location were selected. The collocated data set is obtained by averaging the altimeter measurements, along-track over $50 \mathrm{~km}$ (25 km each side of 
the closest approach). Individual $1 \mathrm{~Hz}$ altimeter wave height measurements are obtained every 7 $\mathrm{km}$ for SARAL and every $5.8 \mathrm{~km}$ for Jason-2, so within this $50 \mathrm{~km}$ distance range it is possible to find up to 7 and 9 individual measurements for SARAL and Jason-2, respectively. Analysis of the dependence of the bias, of the root mean square error (RMSE) and of the seatter index (SI), on the minimum number of along-track averaged observations indicates an optimalplots (not shown) of the root mean square error (RMSE), scatter index (SI) and number of collocated data show that these three parameters decrease with the number of along-track averaged observations. An arbitrary trade-off between scatter and number of collocated data consists in selecting a -number of at least 5 valid data for SARAL, and 6 for Jason-2.

Figure 3 shows the comparison scatter plots for SARAL (left) and Jason-2 (right). Statistics in the gure are given when the outliers (in grey) are not taken into account. The RMSE is less for SARAL $(20 \mathrm{~cm})$ than for Jason-2 $(24 \mathrm{~cm})$. Scatter indexes are almost identical $(0.13)$ for both altimeters. The slope of the regression line is very close to the unity, for SARAL. The SARAL observed mean bias $(8 \mathrm{~cm})$ is slightly larger than the Jason-2 one $(5 \mathrm{~cm})$. The main impact of the outliers is, of course, an increase of RMSE and SI, as shown in columns W and W/O in Table 1.

The dependence of the bias and RMSE on SWH, for both SARAL and Jason-2, is shown in Figure 4. Bias and RMSE are estimated for buoy SWH bins, 0.1 m wide. Better results are obtained with SARAL. The bias is lower for SARAL (top), for SWH less than $0.5 \mathrm{~m}$. The SARAL RMSE is about $20 \mathrm{~cm}$, and also much less than Jason-2 for SWH less than $1 \mathrm{~m}$. The better quality of SARAL SWH is also clearly shown when the results are normalized by the mean SWH of the bin (not shown).

Above statistical results are obtained over the whole buoy data set, with no information on the quality of measurements of each particular buoy. An idea of the distribution of the quality of the various buoys can be obtained in calculating the statistical parameters for each buoy. The bias, RMSE, SI and regression slope were calculated for each buoy having more than 6 collocation data. The histograms for the four parameters are shown in Figure 5. Only very few buoys lead to extreme results. The median value of the parameter is reported and plotted in the graphs. The median value, rather than the mean, can be preferred as it is a robust indicator, not sensitive to 
outliers. The median values are slightly smaller than the mean values reported combining all the collocated data (Figure 3, Table 1).

Separating open ocean and coastal buoys provides interesting results. Figure 6 shows the scatter plots for both SARAL (left) and Jason-2 (right) comparisons with oceanic (top) and coastal (bottom) buoys. Comparison statistical results are also given in Table 1. Fist, all results indicate an increase of the scatter (both RMSE and SI) for coastal buoys. Second, the RMSE is less for SARAL than for Jason-2, for both open ocean and coastal buoys. Without considering outliers, the RMSE increases from $18 \mathrm{~cm}$ (oceanic) to $22 \mathrm{~cm}$ (coastal) for SARAL, and from $21 \mathrm{~cm}$ to 26 cm for Jason-2.

When comparing buoy and satellite data, the different errors should be kept in mind. Inparticular, short wind-waves sampling error already leads to uncertainties on SWH that aretarger than $10 \%$ for 17 -minute long record (Donelan and Pierson 1983). Many other factors can be at the origin of the observed outliers. A main one is the individual buoy instrumental quality. An other one, observed in the present data set, is the relative location of satellite track, buoy and coastal line. Some cases were observed (not shown) of along-track sampling on the other side of a small island, relative to the buoy location. The $10 \mathrm{~Hz}$ high along-track resolution of SARAL is an opportunity for future investigation of such cases.

\section{5- Jason-2 and Cryosat-2 comparison}

SARAL SWH measurements are compared to Jason-2 and Cryosat-2 data, at the ground track crossing points. Three different collocated data set are analysed. The fist one consists in the closest $1 \mathrm{~Hz}$ measurement cells at the crossing ground tracks, within a 30 minute time window. One second measurement cells correspond to along-track distance of the order of $7 \mathrm{~km}$ for SARAL, $5.8 \mathrm{~km}$ for Jason-2, and $6.4 \mathrm{~km}$ for Cryosat-2. The small size of the $1 \mathrm{~Hz}$ "footprint", of the order of ten to twenty $\mathrm{km}$, imposes to consider a short time window, to assume stationary sea state. Half an hour is an usual value, as in buoy wave measurement technology. Twenty to forty minutes is a usually required buoy measurement record length to estimate sea state parameters. Yet, over the 12 first SARAL cycles (about 14 months), the resulting collocated data set consists in 2657 pairs for Jason-2 and 1625 for Cryosat-2, and low and-high (over $6 \mathrm{~m}$ ) 
SWH ranges, over $6 \mathrm{~m}$, -isare poorly sampled. To increase the size of the data set the time window width is increased up to 1 hour, producing the second collocated data set.

Enlarging the time window width also increases the impact of the error induced by the time and space variability of sea state. To compensate for that a third collocated data set is constructed in averaging along-track altimeter measurements over $50 \mathrm{~km}$, i.e. $25 \mathrm{~km}$ each side of the crossing point. Furthermore, for better reliability, data are selected when almost all the $50 \mathrm{~km} 1$ $\mathrm{Hz}$ measurements are valid i.e. when the number of $1 \mathrm{~Hz}$ valid measurements over $50 \mathrm{~km}$, is equal to 6 or 7 for SARAL, to 6,7 or 8 for Cryosat -2 , and to 8 or 9 for Jason-2.

The impact of the time measurement difference is illustrated in Figure 7. showing the bias, the root mean square error and the scatter index for $50 \mathrm{~km}$ along-track averaged, SARAL Jason-2 collocated data, are shown over successive time windows, 1 hour width: time measurement differences between 0 and $1 \mathrm{~h}, 1 \mathrm{~h}$ and $2 \mathrm{~h}, 2 \mathrm{~h}$ and $3 \mathrm{~h}$... up to $12 \mathrm{~h}$. Each time window is one hour wide but the range of the absolute value of the difference between time measurements increases, one hour step, from $0-1 \mathrm{~h}$ to $11 \mathrm{~h}-12 \mathrm{~h}$. The contribution of the time variability is a clear increase of the root mean square error (circle) and of the scatter index (square). Relative to the first time window (plus or minus 1h), the RMSE increases by a factor 5 at 6 h, and 8 at 12 h. The bias (dot) is almost constant, the number of data points number (star), called data number in the following, being uniform (about 5000) over the various time windows. So, for a given space sampling (i.e. $50 \mathrm{~km}$ average) a minimum time difference is suitable, in conjunction with a minimum data number, to eliminate errors due to the time sea state variability.

Comparison results are shown in scatter plots of Figures 8 and 9, and in Tables 2 and 3, for Jason-2 and Cryosat-2, respectively.

Figure 8 shows comparison with Jason-2 corrected SWH, for $1 \mathrm{~Hz}$ (left), and $50 \mathrm{~km}$ average (right) data set. The agreement is very good, over the whole SWH range. Above 8 m-For SWH larger than $8 \mathrm{~m}$, the number of data points is poorsmall and the scatter is larger than at lower SWH. Averaging over $50 \mathrm{~km}$ (right) decreases significantly the scatter: the RMSE decreases from about $20 \mathrm{~cm}$ to $10 \mathrm{~cm}$, and the scatter index from $7 \%$ to $3 \%$; the average distance to the regression line decreases from $14 \mathrm{~cm}$ to $7 \mathrm{~cm}$.

URL: http:/mc.manuscriptcentral.com/umgd Email: marinegeodesy@osu.edu 
Table 2 gives the statistical comparison parameters for the 3 collocated data set $\underline{\text { }}$ ( $1 \mathrm{~Hz}$ and 30 min, $1 \mathrm{~Hz}$ and 1 hour, $50 \mathrm{~km}$ average and 1 hour). A first remark is that increasing the time window width from 30 min to $1 \mathrm{~h}$, increases the number of $1 \mathrm{~Hz}$ collocated data by a factor two (two first columns in the Table 2), but has no significant impact on the results: biases, RMSE, scatter indexes, slopes and intercepts are almost the same for the two data set. This is also observed in Table 3 for Cryosat-2 comparisons.

Though the Jason-2 SWH correction is linear and relatively small, it improves the results of the comparison, for all the statistical parameters in Table 2 (for each collocated data set, the second value of the statistical parameters is given for Jason-2 corrected data), with the exception of the intercept, which slightly increases.

In summary, the SARAL SWH is in very good agreement with Jason-2. The mean bias is less than $2 \mathrm{~cm}$, the root mean square errors are $21 \mathrm{~cm}$ and $10 \mathrm{~cm}$, and scatter index $7 \%$ and $3 \%$, for 1 $\mathrm{Hz}$ and $50 \mathrm{~km}$ average data, respectively. The slope of the regression line is almost equal to the unity.

SARAL Cryosat-2 comparisons are shown in Figure 9. Plots are given for both corrected (right) and non corrected (left) Cryosat-2 data, because of the non linear correction required for Cryosat-2 at low SWH, as indicated above. At very low SWH, Cryosat-2 exhibits some negative values (Figure 9, left). This is feasible because in the waveform processing, SWH is estimated as the root square of a quantity deduced from the return waveform data fitting analysis. At very low sea state, this quantity can be negative, due to the noise. In this case SWH is calculated as the root square of the absolute value, and a negative sign is added to SWH. One of the effects of the proposed correction is to increase this negative values to positive (compare left and right graphs at low SWH). Note that when estimating the correction to Cryosat-2 (Queffeulou 2013b) the negative values of SWH were discarded from the data set, so that the proposed correction could be-not be well adapted to the negative occurrences.

Table 3 shows that, globally, the correction improves the agreement between SARAL and Cryosat-2, in term of bias, RMSE and scatter index (compare the two values given for each parameter). Along-track averaging over $50 \mathrm{~km}$ decreases the RMSE from $22.6 \mathrm{~cm}$ to $13.3 \mathrm{~cm}$ 
and the scatter index from $8 \%$ to $5 \%$, relative to the $1 \mathrm{~Hz}$ data. These comparison results are a bit worse than those obtained with Jason-2.

Variation of the bias and RMSE as a function of SARAL SWH is shown for the various collocated data set, in Figure 10. Upper left graph shows the $1 \mathrm{~Hz}$ SARAL Jason2 comparison. The Jason2 SWH correction (black curves) reduces the bias and the RMSE, relative to the non corrected data (grey curves), over the whole SWH range. Over the $0.5 \mathrm{~m}-6.5 \mathrm{~m}$ SWH range, the bias is very low. Above $6.5 \mathrm{~m} \mathrm{SWH}$, the bias increases with some scatter, that could be due to the relatively low data number small number of data points combined with a larger time variability of SWH at high sea state. The bias variation over the whole SWH range, is much less for the 50 $\mathrm{km}$ average data set (black circle curve in top right graph), space averaging compensating probably for the time variability. This last graph shows a very good agreement between SARAL and Jason-2 corrected data, with RMSE increasing gently from $10 \mathrm{~cm}$ or less, for SWH under 2.5 m, up to $25 \mathrm{~cm}$ for $9 \mathrm{~m} \mathrm{SWH.}$

Results are not so good relative to Cryosat-2 (Figure 10, bottom graphs). The correction reduces the bias for SWH above $1.5 \mathrm{~m}$, resulting bias being less than $10 \mathrm{~cm}$, and the RMSE being of the same order as with Jason-2. But at low SWH, under $1.5 \mathrm{~m}$, the bias increases (the correction changes the sign of the bias) and the RMSE is also higher. This probably results from the inaccuracy of the proposed correction at low negative Cryosat-2 SWH.

The better height measurement resolution of SARAL improves the $1 \mathrm{~Hz}$ SWH accuracy, as shown by the buoy comparison results in section 4, and must also have some impact on the 1 $\mathrm{Hz}$ SWH rms level, which depends on the instrumental noise measurement, and on the geophysical variability of SWH. Comparing density plots of (SWH,rms) pairs for SARAL (Figure 2) with similar plots obtained with other Ku altimeters (not shown here) indicates that the SARAL SWH rms level is much less smaller than for the other altimeters. This is confirmed by the plots of the $1 \mathrm{~Hz}$ SWH rms as a function of SWH at the collocated crossing points (Figure 11). Jason-2 and Cryost-2 exhibit much larger rms than SARAL, and particularly at low SWH, where a significant increase is observed on Cryosat-2. 


\section{6- Conclusion}

The successful launch of the SARAL mission has raised the quality of the available satellite measurements of significant wave height (SWH), once specific flags are applied to the measurements. These flags, essentially based on the standard deviation of SWH estimated from the $40 \mathrm{~Hz}$ data, are designed to exclude specific events due to land or rain contamination. As expected from the high frequency in Ka-band, compared to previous satellite missions, the AltiKa instrument performs better, and particularly for lower sea states, thanks to its narrower range gates.

The buoy comparison shows that SARAL is more accurate than Jason-2 at low SWH. The root mean square error relative to buoys is about $20 \mathrm{~cm}$ for SWH up to $4 \mathrm{~m}$, with no increase at low wave heights, contrary to Jason-2. Global regression analysis also shows that SARAL SWH does not require any correction. Considering uncertainty factors such as the buoy data quality, the relative poor sampling at high and low SWH, or impact of the outliers, present results can be considered as very good. Results from open ocean and coastal buoy comparisons show that SARAL SWH is of better quality than Jason-2, for both situations. The high $10 \mathrm{~Hz}$ along-track resolution of SARAL represents a real opportunity for future investigation of sea state in coastal areas.

The comparison with other altimeters confirms the high quality of the SARAL SWH. The standard deviation of the $1 \mathrm{~Hz}$ measurement is much less than for other altimeters, and particularly at low SWH. It also demonstrates that the corrections applied to Jason-2 and to Cryosat -2 are efficient, improving the comparison results, with the exception of Cryosat-2 at very low SWH. The Cryosat-2 behaviour at low sea state has to be investigated. Considering above good results, SARAL GDR-T SWH data are now included in the Ifremer merged altimeter wave height data base, with no correction, but using the specific SWH flag. The high $40 \mathrm{~Hz}$ along-track resolution of SARAL and the improved accuracy at low SWH represent a real opportunity for future investigation of sea state in coastal areas. The high along-track sampling enables to get measurements closer to the coast, using a running average window over less than one second of data. Nevertheless, the random nature of the specular reflection on the sea surface and the statistical definition of SWH imply that the altimeter SWH $\underline{\text { measurement is typically noisy, and } 40 \mathrm{~Hz} \text { SWH are very noisy. SARAL data will be useful for }}$ 
various coastal application, such as the validation of numerical wave models in coastal waters, and data assimilation in the models. An other field of application is the study of the fetch impact on the wind wave growth.

\section{Acknowledments}

H.H. Sepulveda has been supported by the "Universidad de Concepcion" Fellowship while at the Laboratoire d'Oceanographie Spatiale, at Ifremer. Part of this work has been supported by the Centre National d'Etudes Spatiales in the frame of the TOSCA program. 


\section{References}

Abdalla S., P.A.E.M. Janssen an J.-R. Bidlot. 2010. Jason-2 OGDR wind and wave products: monitoring, validation and assimilation. Marine Geodesy 33: 239-255.

Ardhuin F., J. Tournadre, P. Queffeulou, F. Girard-Ardhuin and F. Collard, Observation and parameterization of small icebergs : drifting breakwaters in the Southern Ocean, Ocean Modelling, 2011, 39:405-410.

Bidlot J.-R., D.J. Holmes, P.A. Wittmann, R. Lalbeharry and H.S. Chen. 2002. Intercomparison of the performance of operational ocean wave forecasting systems with buoy data. Weather and Forecasting 17: 287-310.

Cooper C.K. and G.Z. Forristall. 1997. The use of satellite altimeter data to estimate the extreme wave climate. Journal of Atmospheric and Oceanic Technology 14: 254-266.

Donelan M. and W.J. Pierson. 1983. The sampling variability of estimates of spectra of wind= senerated gravity waves. Journal of Geophysical Research 88: 1381-4392.

Durant T.H., D.J.M. Greenslade and I. Simmonds. 2009. Validation of Jason-1 and Envisat remotely sensed wave heights. Journal of Atmospheric and Oceanic Technology 26: 123-134.

Francis C.R. et al. 2007. CryoSat Mission and Data Description.ESA: CS-RP-ESA-SY-0059, Issue 3 , 2 Jan 2007

Hanafin J., Y. Quilfen, F. Ardhuin, J. Sienkiewicz, P. Queffeulou, M. Obrebski, B. Chapron, N. Reul, F. Collard, D. Corman, E. de Azevedo, D. Vandemark and E. Stutzmann. 2012. Phenomenal sea states and swell from a North Atlantic Storm in February 2011: a comprehensive analysis. Bulletin of American Meteorological Society, doi: 10.1175/BAMS-D-11-00128.1 
Picot N., K. Case, S. Desai and P. Vincent. 2003. AVISO and PODAAC User Handbook. IGDR and GDR Jason Products, SMM-MU-M5-OP-13184-CN (AVISO), JPL D-21352 (PODAAC).

Queffeulou P. 2013-a. Merged altimeter data base. An update. Proceedings ESA Living Planet Symposium 2013, Edimburgh, UK, ,9-13 September 2013, ESA SP-722, December 2013.

Available from:

ftp://ftp.ifremer.fr/ifremer/cersat/products/swath/altimeters/waves/documentation/publication s/ESA_Living_Planet_Symposium_2013.pdf

Queffeulou P. 2013-b. Cryosat-2 IGDR SWH assessment update, May 2013. Laboratoire d’Océanographie Spatiale, IFREMER, Z.I. de la Pointe du Diable, CS10070, 29280 Plouzané, France. Available from:

ftp://ftp.ifremer.fr/ifremer/cersat/products/swath/altimeters/waves/documentation/cryosat_2_i gdr_swh_assessment_update.pdf

Queffeulou P. 2004. Long term validation of wave height measurements from altimeters. Marine Geodesy 27, 495-510.

Queffeulou P. and D. Croizé-Fillon. 2013. Global altimeter SWH data set, version 10, May 2013,

Laboratoire d’ Océanographie Spatiale, IFREMER, Z.I. de la Pointe du Diable, CS10070, 29280 Plouzané, France.

Available from:

ftp://ftp.ifremer.fr/ifremer/cersat/products/swath/altimeters/waves/documentation/altimeter_w ave_merge_10.pdf

Raney R.K. and L. Phalippou. 2011. The future of coastal altimetry. 535-560. S. Vignudelli et al. (eds.), Coastal Altimetry, Springer. ISBN: 978-3-642-12795-3.

Rascle N., F. Ardhuin, P. Queffeulou and D. Croizé-Fillon. 2008. A global wave parameter 
for the open ocean based on traditional parametrizations. Ocean Modelling 25:154-171.

Rascle N. and F. Ardhuin. 2013. A global wave parameter database for geophysical applications. Part 2: model validation with improved source term parametrization. Ocean Modelling 70: 174$\underline{188 .}$

Ray R.D. and B.D. Beckley. 2012. Calibration of ocean wave measurements by the TOPEX, Jason-1, and Jason-2 satellites. Marine Geodesy 35(S1): 238-257.

SARAL/AltiKa Products Handbook (2013). CNES : SALP-MU-M-OP-15984-CN , Issue 2, rev 3 , July 19, 2013.

Shanas P.R., V. Sanil Kumar and N.K. Hithin. 2014. Comparison of gridded multi-mission and along-track mono-mission satellite altimletry wave heughts with in situ near-shore buoy data. Ocean Engineering 83: 24-35.

Skandrani C., J.-M. Lefevre and P. Queffeulou. 2004. Impact of multisatellite altimeter data assimilation on wave analysis and forecast. Marine Geodesy 27:511-533.

Tournadre J., J. Lambin and N. Steunou. 2009. Cloud and rain effects on ALTIKA/SARAL Ka band radar altimeter. Part I: modeling and mean annual data availability. IEEE Transactions on Geoscience and Remote Sensing 47 (6): 1806-1817.

Verron J., P. Sengenes, J. Lambin, J. Noubel, N. Steunou, A. Guillot, N. Picot, S. Coutin-Faye, R. Gairola, D.V.A. Raghava Murthy, J. Richman, D. Gri $\square$ n, A. Pascual, F. Rémy and P. A. Gupta. 2014. The SARAL/AltiKa altimetry satellite mission. Marine Geodesy this issue.

Vincent P., N. Steunou, E. Caubet, L. Phalippou, L. Rey, E. Thouvenot, and J. Verron. 2006. AltiKa: a Ka-band Altimetry Payload and System for Operational Altimetry during the GMES Period. Sensors 6: 208-234. 
Young I.R., S. Zieger and A.V. Babanin. 2011. Global trends in wind speed and wave height. Science 332: 451:455.

Zieger S., J. Vinoth,J. and I.R. Young. 2009. Joint calibration of multiplatform altimeter measurements of wind speed and wave height over the past 20 years. Journal of Atmospheric and Oceanic Technology 26: 2549-2564.

12
13
14
15
16
17
18
19
20
21
22
23
24
25
26
27
28
29
30
31
32
33
34
35
36
37
38
39
40
41
42
43
44
45
46
47
48
49
50
51
52
53
54
55
56
57
58
59
60

URL: http:/mc.manuscriptcentral.com/umgd Email: marinegeodesy@osu.edu 
Figure captions

Figure 1: measurements along SARAL (pass 954, cycle 2) and Jason-2 (pass 244, cycle 179) collocated tracks, between $2^{\circ} \quad \mathrm{S}$ and $4^{\circ} \quad \mathrm{N}$ : $1 \mathrm{~Hz}$ SWH, SWH rms, and SARAL atmospheric backscatter coefficient correction (shifted by $3 \mathrm{~dB}$ ).

Figure 2: density plot $(\log 10)$ of the distribution of SARAL $1 \mathrm{~Hz}$ SWH, SWH rms data, for 0.01 m x $0.01 \mathrm{~m}$ bins, over cycle number 4 to 8 . Solid red line is the estimated maximum SWH rms threshold.

Figure 3: SARAL (left) and Jason-2 (right) SWH comparison with buoy data. Discarded outliers in grey. Orthogonal regression line in grey, and perfect line in dashed grey.

Figure 4: SARAL and Jason-2 buoy comparison. Bias and RMSE as a function of SWH.

Figure 5: SARAL individual buoy comparisons. Histograms of statistical parameters: bias, root mean square error, scatter index and slope coefficient, estimated from individual buoy comparisons. Median value reported (grey) in the graph for each parameter.

Figure 6: SARAL (left) and Jason-2 (right) SWH comparison with buoy data, for open ocean buoys (top) and coastal buoys (bottom). Discarded outliers in grey. Orthogonal regression line in grey, and perfect line in dashed grey.

Figure 7: statistical parameters for SARAL Jason-2 $50 \mathrm{~km}$ along-track averaged collocated data over successive time windows, 1 hour width, ranging from 0 -1h to $11 \mathrm{~h}-12$.

Figure 8 : SARAL Jason-2 SWH comparison: $1 \mathrm{~Hz}$ (left) and $50 \mathrm{~km}$ along-track average (right) collocated data within 1 hour time window.

Figure 9: SARAL Cryosat-2 SWH comparison: $1 \mathrm{~Hz}$ (top) and $50 \mathrm{~km}$ along-track average 
(bottom) collocated data within 1 hour time window, for Cryosat-2 (left) and Cryosat-2 corrected SWH (right).

Figure 10: statistical parameters as a function of SARAL SWH (0.5 m bins) for $1 \mathrm{~Hz}$ (left) and 50 km average (right) collocated data, for Jason-2 (top) and Cryosat-2 (bottom) comparisons. Bias (circles), root mean square error (squares), and number of data points (dots). Jason-2 or Cryosat-2 corrected data in black, non corrected data in grey.

Figure 11: comparison of $1 \mathrm{~Hz} \mathrm{SWH}$ rms as a function of SWH, for collocated data set: SARAL Jason-2 (top), SARAL Cryosat-2 (bottom). Mean value of rms per SWH 0.1 m bins, in grey. 
Table 1: statistical parameters for SARAL and Jason-2 SWH measurements, versus buoy observations. Data number, bias (cm), RMSE (cm) and scatter index, for a) all pairs of data, b) for data pairs from coastal buoys, c) for data pairs from oceanic buoys. In each case, results are given with outliers (column W) and without outliers (column W/O).

\begin{tabular}{|c|c|c|c|c|c|c|c|c|c|c|c|c|}
\hline & \multicolumn{6}{|c|}{ SARAL } & \multicolumn{6}{|c|}{ JASON 2} \\
\hline & \multicolumn{2}{|l|}{ All } & \multicolumn{2}{|c|}{ Coastal } & \multicolumn{2}{|c|}{ Oceanic } & \multicolumn{2}{|l|}{ All } & \multicolumn{2}{|c|}{ Coastal } & \multicolumn{2}{|c|}{ Oceanic } \\
\hline & W & $\mathrm{W} / \mathrm{O}$ & W & $\mathrm{W} / \mathrm{O}$ & W & $\mathrm{W} / \mathrm{O}$ & W & $\mathrm{W} / \mathrm{O}$ & W & $\mathrm{W} / \mathrm{O}$ & W & $\mathrm{W} / \mathrm{O}$ \\
\hline $\mathrm{n}$ & 6718 & 6390 & 3425 & 3197 & 3194 & 3106 & 7843 & 7504 & 3727 & 3271 & 4272 & 4096 \\
\hline bias & 8 & 8 & 10 & 8 & 6 & 7 & 3 & 5 & 11 & 7 & 2 & 3 \\
\hline rmse & 30 & 20 & 34 & 22 & 23 & 18 & 38 & 24 & 44 & 26 & 28 & 21 \\
\hline si & 0.18 & 0.13 & 0.23 & 0.16 & 0.13 & 0.10 & 0.19 & 0.13 & 0.25 & 0.16 & 0.13 & 0.10 \\
\hline
\end{tabular}


Table 2: Saral Jason-2 SWH comparison for 3 collocated data set: $1 \mathrm{~Hz}$ measurement cells within 30 min or 1 hour time window, and $50 \mathrm{~km}$ along-track averages within 1 hour time window. Datanumber, SWH bias, root mean square error, scatter index, orthogonal regression slope and intercept. For each parameter the second value is obtained when the Jason-2 SWH is corrected. $\underline{\text { Comparison of Saral and Jason-2 SWH for } 3 \text { collocated data sets: } 1 \mathrm{~Hz} \text { measurement cells at }}$ crossover within $30 \mathrm{~min}$ or 1 hour time window, and $50 \mathrm{~km}$ along-track averages within 1 hour time window. Number of data points, SWH bias, root mean square error, scatter index, orthogonal $\underline{\text { regression slope and intercept, are given for Jason-2 non corrected (NC) and corrected (C) data. }}$

\begin{tabular}{|l|l|l|l|l|l|l|}
\hline & \multicolumn{2}{|l|}{ Crossover 30 min } & \multicolumn{2}{c|}{ Crossover 1 hour } & 50 km average 1 hour \\
\hline & \multicolumn{2}{|l|}{2657} & \multicolumn{2}{c|}{5272} & \multicolumn{2}{c|}{4849} \\
\hline & NC & C & NC & C & NC & C \\
\hline bias $(\mathrm{cm})$ & 5.5 & -1.7 & 5.4 & -1.8 & 5.7 & -1.7 \\
\hline rmse $(\mathrm{cm})$ & 20.7 & 19.8 & 21.6 & 20.9 & 11.8 & 10.1 \\
\hline si & 0.07 & 0.06 & 0.07 & 0.07 & 0.04 & 0.03 \\
\hline slope & 0.9710 & 0.9855 & 0.9739 & 0.9884 & 0.9789 & 0.9935 \\
\hline intercept $(\mathrm{cm})$ & 3.25 & 6.07 & 2.51 & 5.32 & 0.90 & 3.68 \\
\hline
\end{tabular}

URL: http:/mc.manuscriptcentral.com/umgd Email: marinegeodesy@osu.edu 
Table 3: as Table 2, for Saral Cryosat-2 collocated data.

Comparison of Saral and Cryosat-2 SWH for 3 collocated data sets: $1 \mathrm{~Hz}$ measurement cells at crossover within $30 \mathrm{~min}$ or 1 hour time window, and $50 \mathrm{~km}$ along-track averages within 1 hour time window. Number of data points, SWH bias, root mean square error, scatter index, orthogonal regression slope and intercept, are given for Cryosat-2 non corrected (NC) and corrected (C) data.

\begin{tabular}{|l|l|l|l|l|l|l|}
\hline & \multicolumn{2}{|c|}{ Crossover 30 min } & \multicolumn{2}{c|}{ Crossover 1 hour } & \multicolumn{2}{c|}{$50 \mathrm{~km}$ average 1 hour } \\
\hline $\mathrm{n}$ & \multicolumn{2}{|c|}{1625} & \multicolumn{2}{c|}{3206} & \multicolumn{2}{c|}{2841} \\
\hline & NC & C & NC & C & NC & C \\
\hline bias $(\mathrm{cm})$ & -8.9 & -5.9 & -8.5 & -5.5 & -9.03 & -4.95 \\
\hline rmse $(\mathrm{cm})$ & 24.7 & 21.4 & 25.6 & 22.6 & 16.2 & 13.3 \\
\hline si & 0.09 & 0.08 & 0.09 & 0.08 & 0.06 & 0.05 \\
\hline slope & 1.0250 & 0.9861 & 1.0175 & 0.9815 & 1.0063 & 0.9782 \\
\hline intercept $(\mathrm{cm})$ & 2.19 & 9.65 & 3.79 & 10.52 & 7.27 & 11.12 \\
\hline
\end{tabular}


Figure 1: measurements along SARAL (pass 954, cycle 2) and Jason-2 (pass 244, cycle 179) collocated tracks, between $2^{\circ} \mathrm{S}$ and $4^{\circ} \mathrm{N}: 1 \mathrm{~Hz}$ SWH, SWH rms, and SARAL atmospheric backscatter coefficient correction (shifted by $3 \mathrm{~dB}$ ).

$118 \times 70 \mathrm{~mm}(300 \times 300 \mathrm{DPI})$ 


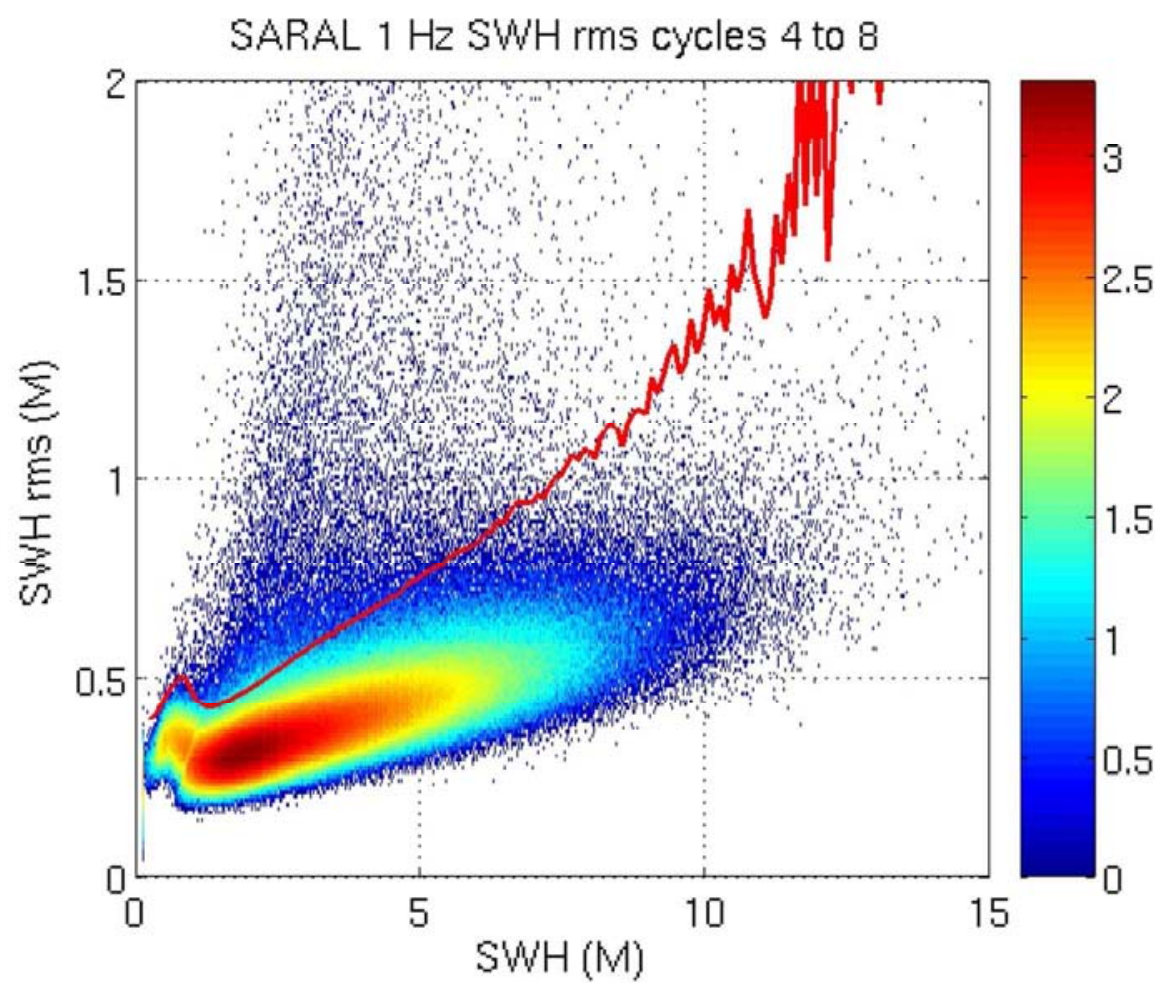

Figure 2: density plot ( $\log 10$ ) of the distribution of SARAL $1 \mathrm{~Hz}$ SWH, SWH rms data, for $0.01 \mathrm{~m} \times 0.01 \mathrm{~m}$ bins, over cycle number 4 to 8 . Solid red line is the estimated maximum SWH rms threshold.

\section{$118 \times 88 \mathrm{~mm}(300 \times 300$ DPI)}



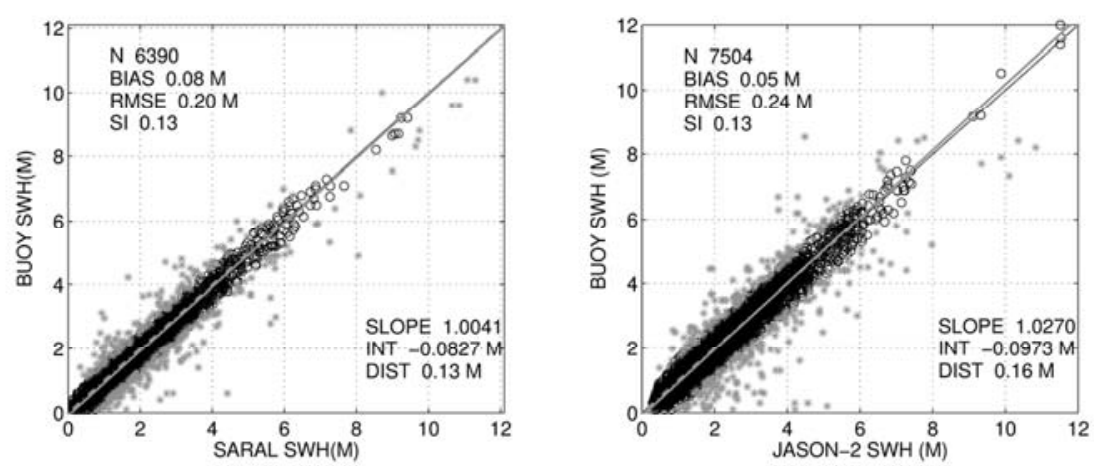

Figure 3: SARAL (left) and Jason-2 (right) SWH comparison with buoy data. Discarded outliers in grey. Orthogonal regression line in grey, and perfect line in dashed grey. $119 \times 43 \mathrm{~mm}(300 \times 300$ DPI $)$ 

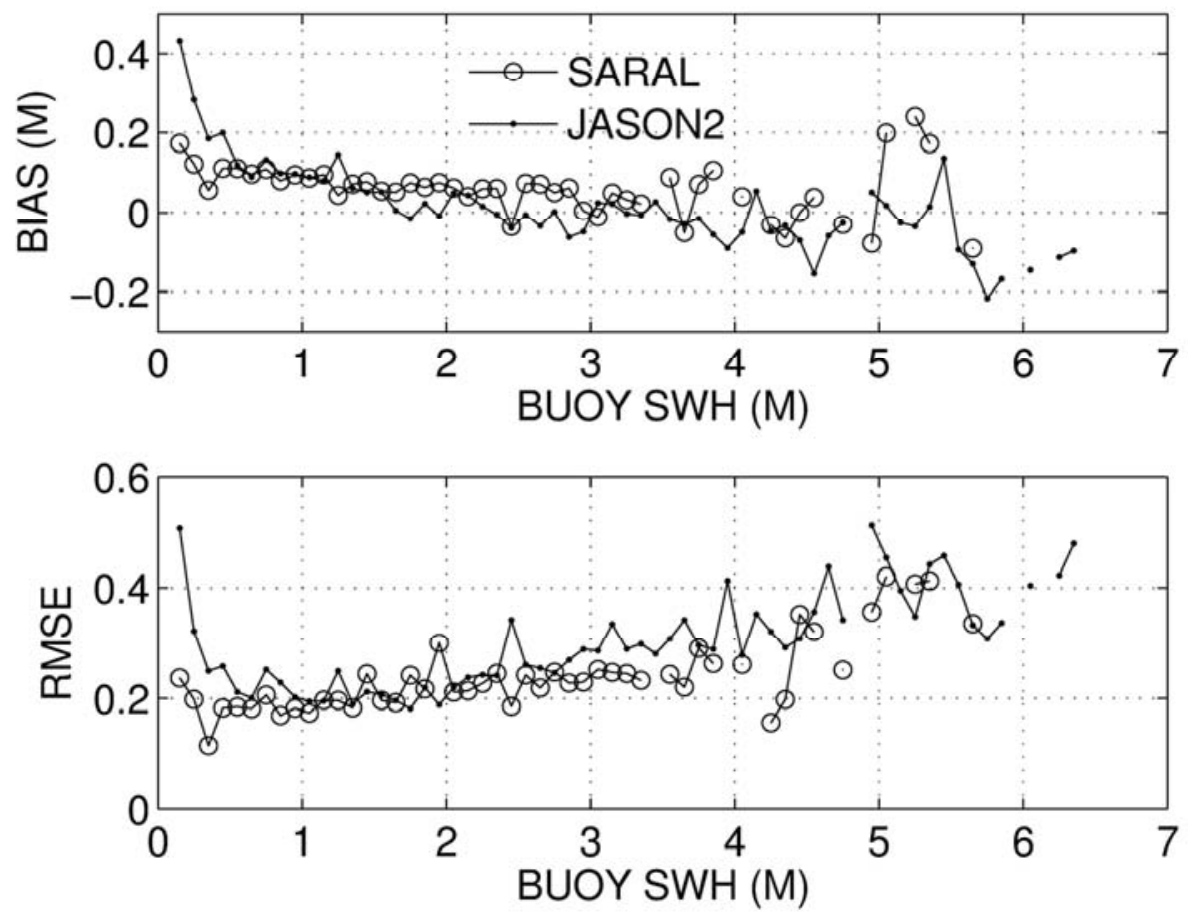

Figure 4: SARAL and Jason-2 buoy comparison. Bias and rmse as a function of SWH. $118 \times 88 \mathrm{~mm}(300 \times 300 \mathrm{DPI})$ 

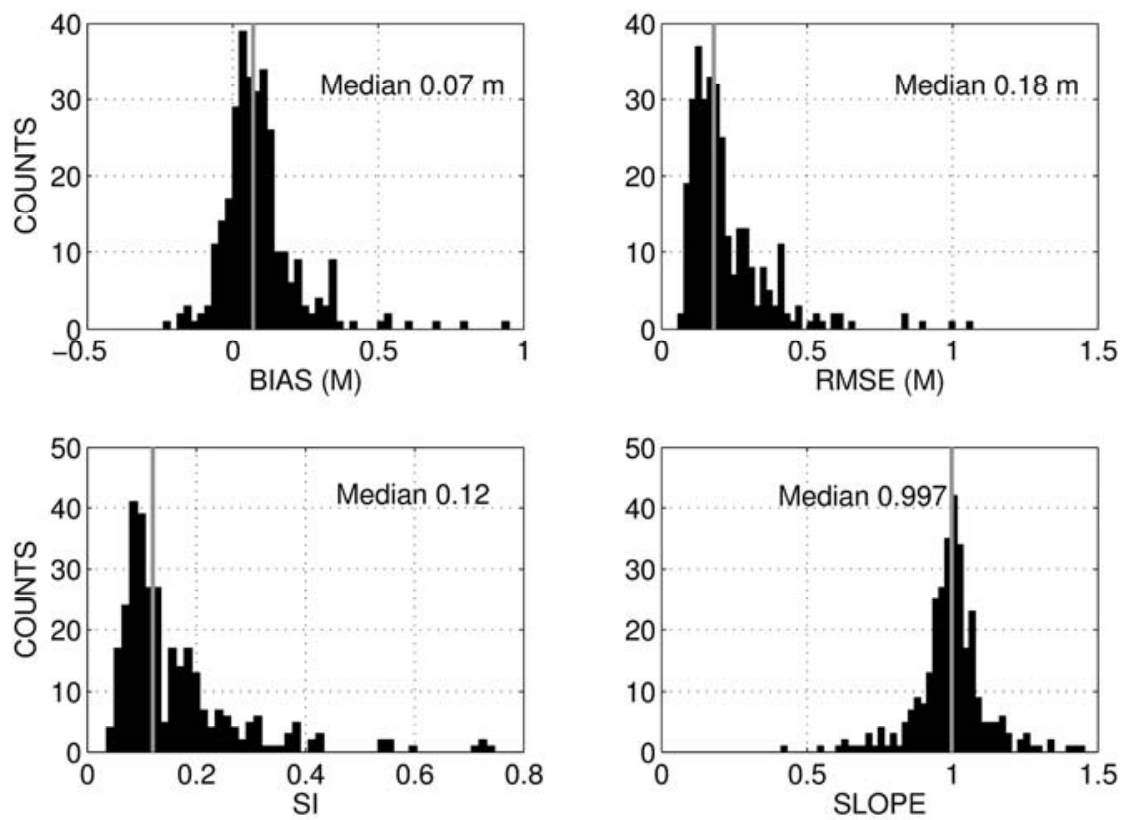

SARAL individual buoy comparisons. Histograms of statistical parameters: bias, root mean square error, scatter index and slope coefficient, estimated from individual buoy comparisons. Median value reported (grey) in the graph for each parameter. $158 \times 109 \mathrm{~mm}(300 \times 300 \mathrm{DPI})$ 

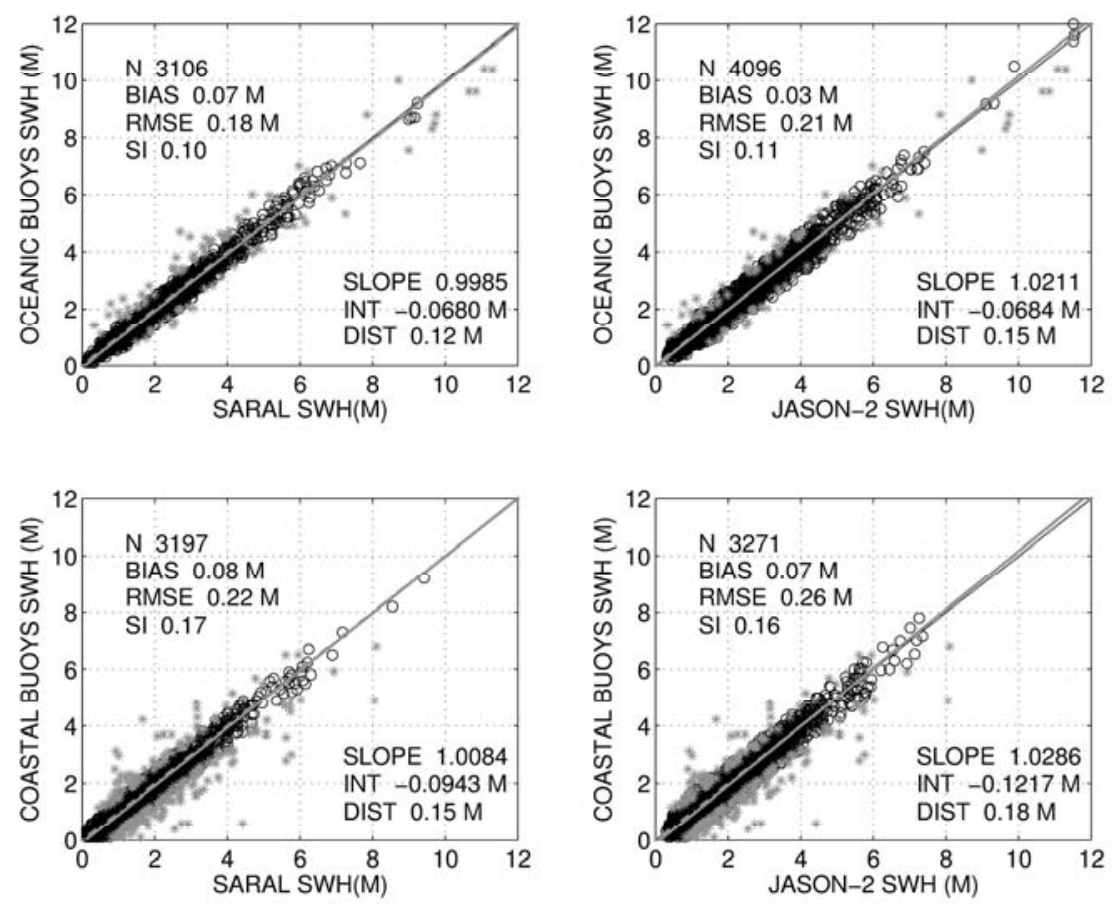

Figure 6: SARAL (left) and Jason-2 (right) SWH comparison with buoy data, for open ocean buoys (top) and coastal buoys (bottom) $208 \times 160 \mathrm{~mm}(300 \times 300$ DPI $)$ 
SARAL JASON-2 COR. $50 \mathrm{~km} 1$ hour time window width

Figure 7: statistical parameters for SARAL Jason-2 $50 \mathrm{~km}$ along-track averaged collocated data over successive time windows, 1 hour width, ranging from $0-1 \mathrm{~h}$ to $11 \mathrm{~h}-12$.

$$
118 \times 89 \mathrm{~mm}(300 \times 300 \text { DPI })
$$




\section{Page 33 of 36}
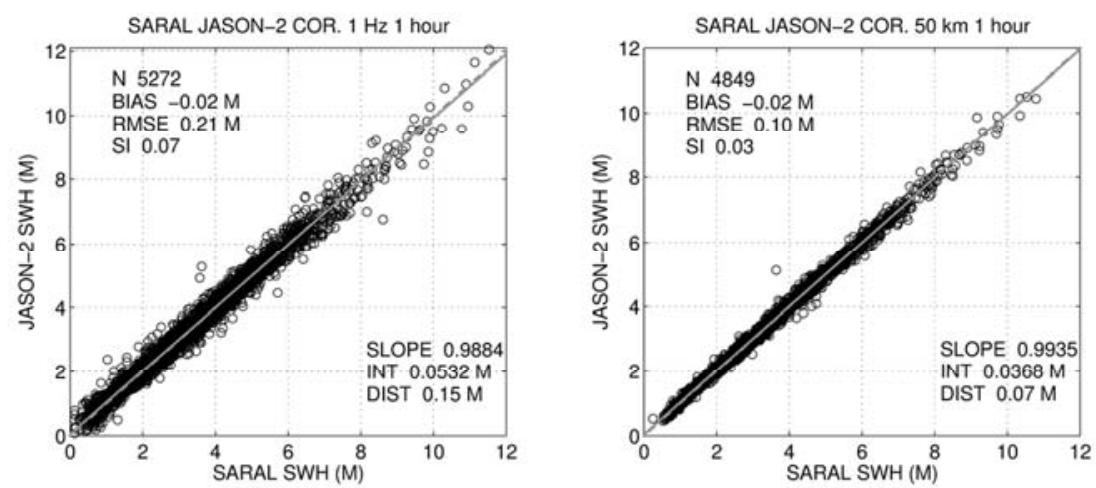

Figure 8 : SARAL Jason-2 SWH comparison: $1 \mathrm{~Hz}$ (left) and $50 \mathrm{~km}$ along-track average (right) collocated data within 1 hour time window. $119 \times 43 \mathrm{~mm}$ (300 x 300 DPI) 

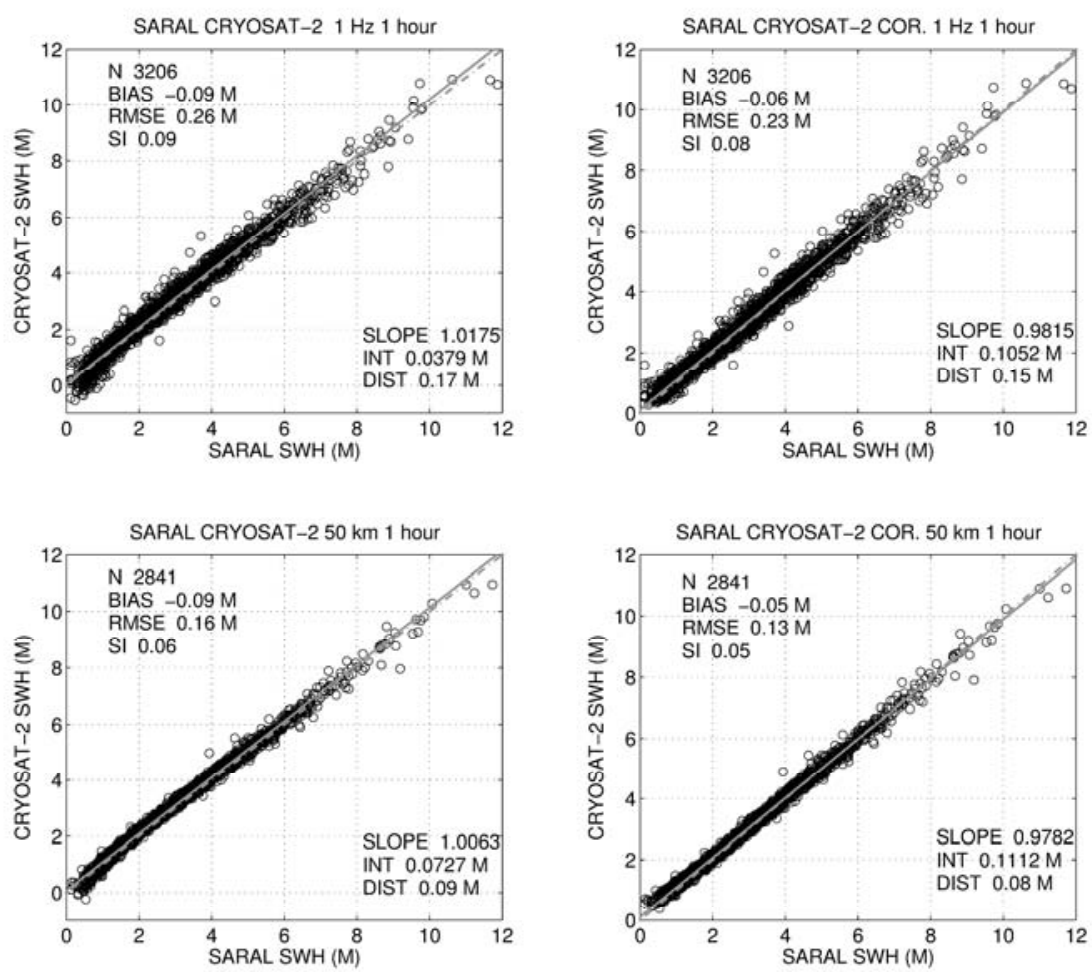

Figure 9: SARAL Cryosat-2 SWH comparison: $1 \mathrm{~Hz}$ (top) and $50 \mathrm{~km}$ along-track average (bottom) collocated data within 1 hour time window, for Cryosat-2 (left) and Cryosat-2 corrected SWH (right). $266 \times 219 \mathrm{~mm}(300 \times 300 \mathrm{DPI})$ 

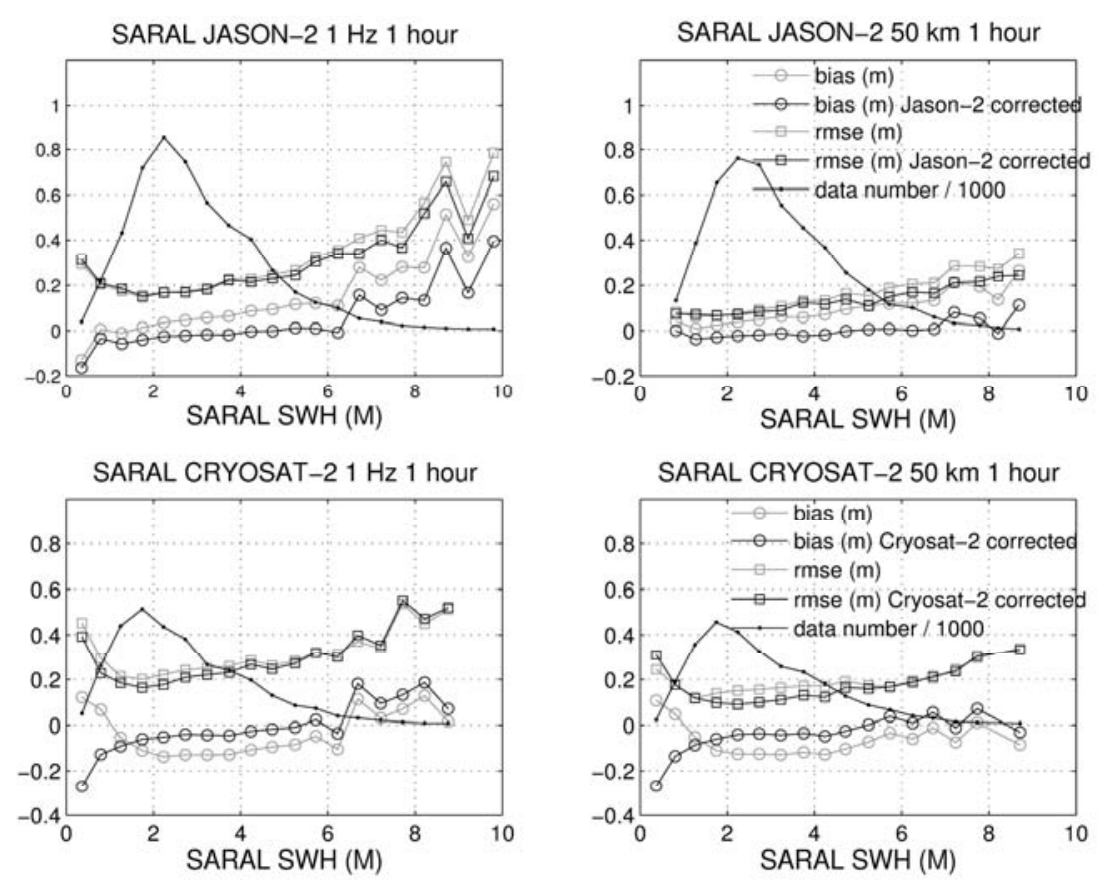

statistical parameters as a function of SARAL SWH ( $0.5 \mathrm{~m}$ bins) for $1 \mathrm{~Hz}$ (left) and $50 \mathrm{~km}$ average (right) collocated data, for Jason-2 (top) and Cryosat-2 (bottom) comparisons. Bias (circles), root mean square error (squares), and number of data points (dots). Jason-2 or Cryosat-2 corrected data in black, non corrected data in grey. $179 \times 128 \mathrm{~mm}(300 \times 300 \mathrm{DPI})$ 

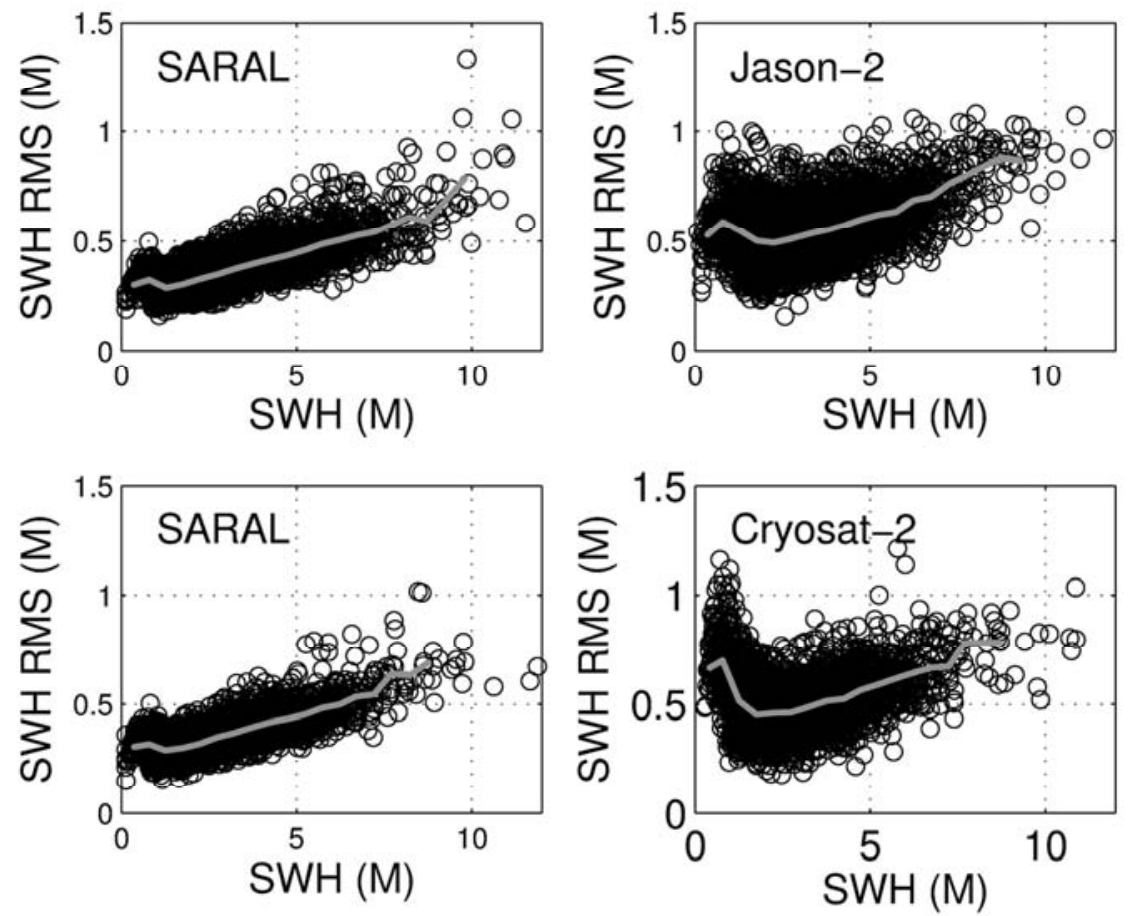

Figure 11: comparison of $1 \mathrm{~Hz}$ SWH rms as a function of SWH, for collocated data set: SARAL Jason-2 (top), SARAL Cryosat-2 (bottom). Mean value of rms per SWH $0.1 \mathrm{~m}$ bins, in grey. $118 \times 88 \mathrm{~mm}(300 \times 300 \mathrm{DPI})$ 